\title{
Gastrointestinal infections in returned travelers
}

\author{
Agnieszka Fedor ${ }^{1}$, Ignacy Bojanowski ${ }^{1}$, Krzysztof Korzeniewski ${ }^{2,3}$ \\ ${ }^{1}$ Students' Scientific Circle of Travel Medicine, Medical University of Warsaw, Poland \\ ${ }^{2}$ Department of Epidemiology and Tropical Medicine; Military Institute of Medicine, Warsaw, Poland \\ ${ }^{3}$ Polish Society of Maritime, Tropical and Travel Medicine, Gdynia, Poland
}

\begin{abstract}
Gastrointestinal infections are one of the most frequent medical conditions diagnosed in patients who travel to tropical or subtropical destinations. The most common disorder occurring in up to $60 \%$ travelling people is travelers' diarrhea (TD). The illness is defined as a minimum of three loose stools within 24 hours; in most cases TD is caused by the enterotoxigenic Escherichia coli. Its symptoms usually persist for 4-5 days and resolve spontaneously or on self-administered empirical antimicrobial therapy, but in case of an invasive infection, it is necessary to seek medical care. As most tourists travel for 1-2 weeks, the disease often persists or develops upon return; therefore, it is important to raise awareness of TD's clinical features and treatment options among physicians from travelers' home countries unaccustomed to this health problem. Another issue, which is gaining more and more importance in recent years, is post-infectious irritable bowel syndrome, a chronic disturbance affecting up to $17 \%$ of patients, who have had travelers' diarrhea. This review aims to promote prophylaxis of gastrointestinal disorders and to extend knowledge about their after-effects in returned travelers.
\end{abstract}

(Int Marit Health 2019; 70, 4: 244-251)

Key words: gastrointestinal infections, travelers' diarrhea, treatment, prophylaxis

\section{INTRODUCTION}

Gastrointestinal (GI) infections are one of the most frequent health problems among people travelling to low income countries [1, 2], which may greatly affect tourists' holiday or business plans [3]. Among the etiological factors bacteria were found to be the most common, but viruses and parasites may also be responsible for Gl infections. The risk factors commonly associated with $\mathrm{Gl}$ infections include lack of compliance with hygiene practices, drinking tap water or eating food of unknown origin [4]. Travelers' diarrhea (TD) is by far the most common Gl infection among travelling people $[4,5]$. Its symptoms usually appear within the first 1-2 weeks of travel; in $10 \%$ of patients can persist more than a week [1], although the median duration is 2 days [6]. As exotic destinations are becoming increasingly popular among tourists, physicians working in developed countries are now more likely to see patients presenting with a travel-related health problem which persists or develops upon return.

\section{EPIDEMIOLOGY}

About half a billion people from developed countries travel internationally each year, of whom as many as 100 million travel to a developing regions of the world [4]. Among the latter, $60 \%$ will develop diarrhea [7], and $8 \%$ will seek medical help during or shortly after travel. The age groups that are most likely to be affected by Gl disorders include children (younger than 2 years old) and young adults [4]. The most common GI infection, i.e. TD [4, 5], occurs in $20 \%$ to $50 \%$ of travelers [6] (the indexes depending on a source), or 11 million of travelling people annually [3]. A total of $17 \%$ of patients return home with clinical manifestations of the disease, and $2 \%$ develop symptoms after their return [6]. Gl infections are a common problem which requires pre-travel advice. It is worth noting that in the last 20 years the number of TD cases during a 2-week trip has decreased remarkably, from $65 \%$ to $10-40 \%$ depending on the destination (Fig. 1) [8]. 


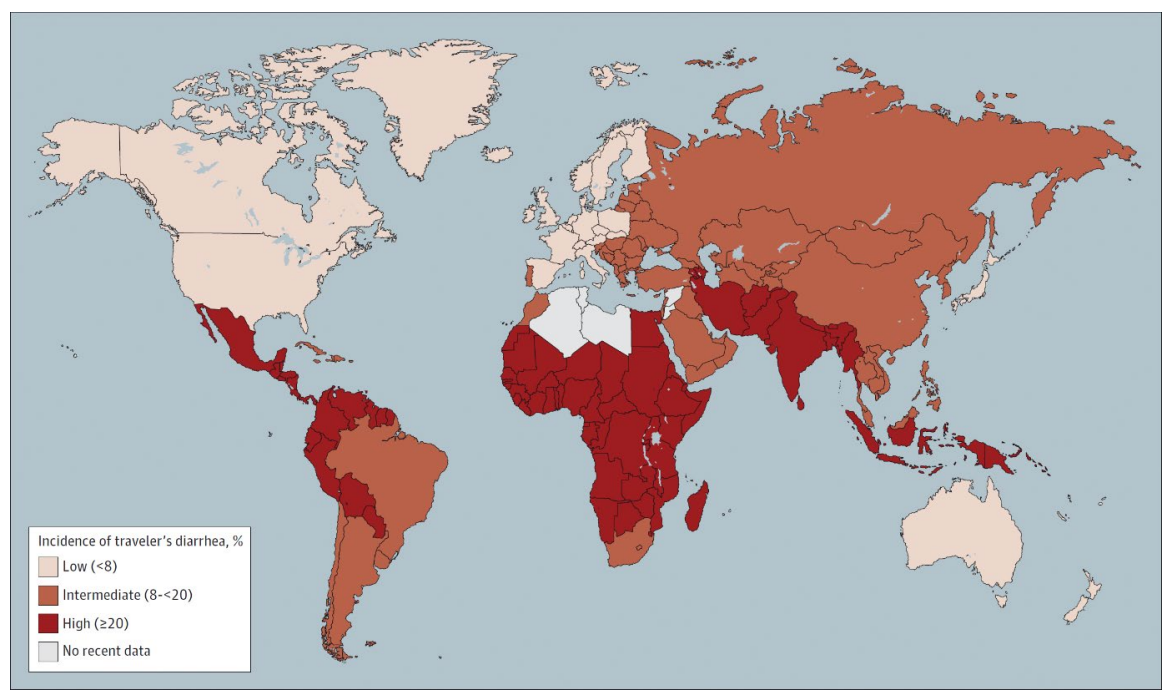

Figure 1. Incidence rates of travelers' diarrhea in the initial 2 weeks of stay in various regions of the world among visitors residing in industrialized countries, 1996-2008. Source: Steffen R, Hill DR, DuPont HL. Traveler's diarrhea: a clinical review. JAMA 2015; 313: 71-80 [8]

\section{RISK FACTORS}

Most cases of Gl infections are transmitted through the fecal-oral route [9]. For this reason, most, if not all, risk factors are related to hygiene and eating habits. The major risk factors can be broadly divided into two categories: environmental and host hazards. The most important of the environmental hazards is the travel destination. The highest risk for $\mathrm{Gl}$ infections is reported from developing countries, which is due to poor standards of sanitation and hygiene $[3,4,9,10]$. The income level is inversely proportional to Gl incidence rates [7]. According to the results of a retrospective observational analysis of 6,086 travelers by an international association of travel medicine clinics, travel to Sub-Saharan Africa, South America and South Asia is associated with the highest risk of Gl infection, with India and Nepal having the highest risk of all countries analysed in the study. This applies to all pathogens responsible for Gl infections (bacteria, parasites, and viruses) [7]. No geographical association has been found for persistent diarrhea [10]. In some regions, such as Northeast Asia and Northern Mediterranean the risk has lowered compared to a study performed in 1986, possibly by the improvement of tourism infrastructure $[4,7]$. Another risk factor is related to the style of travelling. In general, backpacking is said to present a high risk for GI disorders, most likely due to more risky behaviour, such as drinking tap water and eating street food [4]; however, luxury all-inclusive hotels and cruises are not always safer than cheap hostels, because of serving food stored for a long-term [3, 11]. Also, eating in private homes is safer than eating in restaurants [3]. Some foods and beverages are especially risky, e.g. shellfish, which accumulates many pathogens within (Vibrio cholerae, Norovirus, HAV) [4] and drinks with ice cubes, which are usually prepared from tap water (may be contaminated with fecal bacteria) [3]. Travelers need to keep in mind that contact with local animals can result in a Campylobacter or Giardia infection. Another issue to consider is the length of travel and stay. Normally, the longer the trip, the higher the risk of a GI infection [6]. A minimum of 2-week stay in South or Southeast Asia, Middle East and South America holds the highest risk of acquiring a GI disorder [4]. As for the host hazards, the most relevant is the age of a traveller. Teenagers and young adults are in the highest risk group $[6,7,11]$, and children are the ones who are the most often hospitalised [11]. There is no difference between sexes as to the risk of acquiring a Gl infection $[6,11]$. People with hypochlorhydria and patients treated with antacids are more likely to fall ill $[11,12]$ as higher level of gastric acid would have had bactericidal effect. Some genetic features, although rarely assessed [11], give an interesting insight into travel infections - people with blood group 0 or with mutation in interleukin (IL)-8 [3, 4], lactoferrin or IL-10 [4] gene, are prone to TD [3]. Immunocompromised patients are also more likely to acquire a Gl illness during travel, and are more often diagnosed with protozoan infections [3], which may lead to persistent diarrhea.

\section{TRAVELERS' DIARRHEA}

Travelers' diarrhea is defined as 3 or more stools per day, sometimes with additional symptoms, such as abdominal cramps, tenesmus, nausea, vomiting, fever, chills or prostration, all starting during or shortly after travel. In $5-15 \%$ cases of diarrhea blood or mucus may occur in stools (dysentery) [13]. The World Health Organization adds the number of stools greater than normal for a relevant individual to the definition [11]. TD occurs as a result of 
Table 1. Distribution of pathogens in acute cases of travelers' diarrhea by geographical region

\begin{tabular}{|c|c|c|c|c|}
\hline Pathogen & $\begin{array}{l}\text { Latin } \\
\text { America (\%) }\end{array}$ & $\begin{array}{l}\text { Asia } \\
(\%)\end{array}$ & $\begin{array}{l}\text { Africa } \\
\text { (\%) }\end{array}$ & $\begin{array}{l}\text { Middle } \\
\text { East (\%) }\end{array}$ \\
\hline $\begin{array}{l}\text { Enterotoxigenic } \\
\text { E. coli }\end{array}$ & $17-70$ & $6-37$ & $8-42$ & $29-33$ \\
\hline $\begin{array}{l}\text { Enteroinvasive } \\
\text { E. coli }\end{array}$ & $2-7$ & $2-3$ & $0-2$ & 1 \\
\hline $\begin{array}{l}\text { Other E. coli } \\
\text { (EPEC, EAEC, EHEC) }\end{array}$ & $5-15$ & 1 & $2-7$ & NA \\
\hline Shigella spp. & $2-30$ & $0-17$ & $0-9$ & $8-26$ \\
\hline Salmonella spp. & $1-16$ & $1-33$ & $4-25$ & 2 \\
\hline $\begin{array}{l}\text { Campylobacter } \\
\text { jejuni }\end{array}$ & $1-5$ & $9-39$ & $1-28$ & $1-2$ \\
\hline Aeromonas spp. & $1-5$ & $1-57$ & $0-9$ & 1 \\
\hline $\begin{array}{l}\text { Plesiomonas } \\
\text { shigelloides }\end{array}$ & $0-6$ & $3-13$ & $3-5$ & 1 \\
\hline $\begin{array}{l}\text { Vibrio cholerae } \\
\text { non-01 }\end{array}$ & $0-2$ & $1-7$ & $0-4$ & 2 \\
\hline Yersinia spp. & NA & $0-3$ & NA & 1 \\
\hline Rotavirus spp. & $0-6$ & $1-8$ & $0-36$ & NA \\
\hline $\begin{array}{l}\text { Entamoeba } \\
\text { histolytica }\end{array}$ & NA & $5-11$ & $2-9$ & NA \\
\hline Giardia intestinalis & $1-2$ & $1-12$ & $0-1$ & NA \\
\hline $\begin{array}{l}\text { Cryptosporidium } \\
\text { spp. }\end{array}$ & NA & $1-5$ & 2 & NA \\
\hline $\begin{array}{l}\text { No pathogen } \\
\text { identified }\end{array}$ & $24-62$ & $10-56$ & $15-53$ & $50-51$ \\
\hline
\end{tabular}

NA - not available; Source: Castelli F, Pezzoli C, Tomasoni L. Epidemiology of travelers' diarrhea. J Travel Med. 2001; 8(Suppl. 2): S26-S30 [19]

exposure to local enteric pathogens during international relocation.

Etiology. The pathogen causing TD is identified in only $40-60 \%$ of travelers with symptoms. The identification of the pathogen is not always needed, considering the symptoms are usually either self-limiting or disappear rapidly after empirical self-administered therapy [3]. However, when diagnosed, the predominant pathogen worldwide is the enterotoxigenic Escherichia coli (ETEC) [2, 4, 12, 14] (Table 1). ETEC has been identified in $33.6 \%$ of patients suffering from TD in South America, 31.2\% in Africa and $30.1 \%$ in South Asia. According to different sources, from 50 to $85 \%$ cases of TD are caused by bacteria [2,3], whereas $10-15 \%$ of cases are caused by viruses, mostly in Africa and South America [15]. Parasites are estimated to cause $17 \%$ of TD cases, and are often identified in patients with persistent diarrhea [3]. However, even 34-41\% cases are caused by a mixed infection, the frequent co-pathogens being ETEC and EAEC (enteroaggregative E. coli) [4]. ETEC,
EAEC, Campylobacter, Salmonella, Shigella and Vibrio spp. are the most common bacteria found in patients with TD $[2,4,16]$. Others have specific geographical distribution, e.g. Aeromonas spp. and Plesiomonas shigelloides are often found in Asia [3] while Campylobacter spp. has been the most identified pathogen in travelers to Southeast Asia (32\%), which is important to remember when adjusting the treatment, as there is a high resistance of these strains to commonly used ciprofloxacin [4]. Viruses, especially the norovirus species, are often connected with outbreaks of the illness in small travel communities such as passengers of a cruise ship $[3,17]$. Rotavirus infection is a common diarrhea cause in travelers to Mexico [2]. Giardia intestinalis and Entamoeba histolytica are the most common protozoa causing TD, although $E$. histolytica is thought to be overdiagnosed as it is indistinguishable microscopically from its harmless cousin E. dispar. Giardia, Cyclospora and Cryptosporidium parvum are often identified in returned travelers with persistent diarrhea $[9,18,19]$. Russia and Nepal are locations where parasites are commonly identified among travelers with diarrhea [2].

Some cases of acute diarrhea with short incubation period may be a consequence of consuming toxins which have already been released by bacteria, mostly in food which has not been stored properly. The most common toxin-producing bacteria include Clostridium perfringens, Staphylococcus aureus, Bacillus cereus and Clostridium botulinum. The most threatening infections are by $C$. perfringens type $C$ (they may lead to necrosis of the intestine wall) and by $C$. botulinum (with subsequent injury of the nervous system) [2]. A non-infectious cause of TD is ciguatoxin which accumulates in big reef fish in the Pacific and the Caribbean area. It causes acute diarrhea followed by neurological symptoms [20].

Clinical course. According to the statistics, the onset of symptoms occurs most frequently either on the first 3-4 days abroad or on the $10^{\text {th }}$ day of the trip (Table 2). The untreated TD lasts 4 days [4], while half of the patients recover even faster - within 48 hours. The mean duration of patient's incapacity is less than 1 day [8]. TD has a wide range of course paths, from self-limiting indisposition to a serious condition with a need of hospitalisation. In $1 \%$ of cases TD evolves from an acute distress to a chronic disease and sometimes it may have long-term consequences on the overall health of the patient $[4,11]$ causing, among others, post-infectious irritable bowel syndrome (PI-IBS) [8]. In most cases the clinical course is mild and diarrhea consists of no more than 5 stools per day, while accompanying symptoms are nothing more but nausea and abdominal pain [4]. 1\% of patients require hospitalisation. General practitioners who encounter patients with diarrhea returning from a travel should be aware of the impact this 
Table 2. Etiology and clinical symptoms of gastrointestinal disorders in returned travelers

\begin{tabular}{|c|c|c|c|}
\hline Etiology & Incubation period & Symptoms & Duration of symptoms \\
\hline Campylobacter jejuni & $2-5$ days & Fever, abdominal pain, vomiting, diarrhea & $2-10$ days \\
\hline Clostridium difficile & 5 days -5 months & Fever, abdominal pain, diarrhea & 4 days - weeks \\
\hline Escherichia coli 0157:H7 & $1-8$ days & $\begin{array}{l}\text { Abdominal pain, vomiting, acute diarrhea } \\
\text { often with blood }\end{array}$ & $5-10$ days \\
\hline Enterotoxigenic Escherichia coli (ETEC) & $1-3$ days & Abdominal pain, watery diarrhea & 3-7 days \\
\hline Salmonella enteritidis & $1-3$ days & Fever, abdominal pain, vomiting, diarrhea & 4-7 days \\
\hline Shigella spp. & $24-48 \mathrm{~h}$ & Fever, abdominal pain & 4-7 days \\
\hline Vibrio cholerae & $24-72 h$ & $\begin{array}{l}\text { Life threatening dehydration caused by } \\
\text { watery diarrhea and vomiting }\end{array}$ & 3-7 days \\
\hline Vibrio parahaemolyticus & $2-48 \mathrm{~h}$ & $\begin{array}{l}\text { Watery diarrhea, abdominal pain, nausea, } \\
\text { vomiting }\end{array}$ & $2-5$ days \\
\hline Yersinia enterocolitica & $24-48 h$ & $\begin{array}{l}\text { Fever, abdominal pain, vomiting, diarrhea } \\
\text { with blood }\end{array}$ & $1-3$ weeks \\
\hline Norovirus & $12-48 \mathrm{~h}$ & $\begin{array}{l}\text { Fever, muscle pain, abdominal pain, nausea, } \\
\text { vomiting, diarrhea }\end{array}$ & $12-60 \mathrm{~h}$ \\
\hline Rotavirus & $24-72 \mathrm{~h}$ & Fever, nausea, vomiting, watery diarrhea & $4-10$ days \\
\hline Giardia intestinalis & $9-15$ days & $\begin{array}{l}\text { Persistent diarrhea, abdominal pain, bloating, } \\
\text { weight loss }\end{array}$ & $>14$ days \\
\hline Entamoeba histolytica & $8-30$ days & $\begin{array}{l}\text { Diarrhea with mucus and blood, abdominal } \\
\text { pain; chronic type of amoebiasis (amoebic liver } \\
\text { abscess) }\end{array}$ & $>14$ days \\
\hline Cryptosporidium parvum & $3-12$ days & $\begin{array}{l}\text { Watery diarrhea, abdominal pain, nausea, } \\
\text { vomiting, weight loss }\end{array}$ & $>14$ days \\
\hline
\end{tabular}

Source: Korzeniewski K. Gastrointestinal disorders in returning travellers. FMR 2018; 12(4): 115-126 [4]

disease can have. Diarrhea interferes with absorption of some medications - warfarin and other anticonvulsants as well as oral contraception. Loss of fluids leads to electrolyte disorders and is especially dangerous for young children. Some pathogens, common especially in Southeast Asia, such as Shigella, Salmonella and Campylobacter, can lead to Reiter's syndrome or trigger an inflammatory disease in the intestine. Over 10\% of patients with TD develop post-infectious irritable bowel syndrome [3].

Pathophysiology. Understanding the pathogenesis of TD will suggest the right path of the treatment. Bacteria, the main cause of TD, use colonisation factors (such as fimbriae and pilli) to colonise the intestine; virulence factors like enterotoxins, endotoxins and cytotoxins that cause the symptoms as well as some bacteria invade the intestinal mucosa themselves [9]. ETEC and Vibrio cholerae release enterotoxins in the small intestine. These particles increase levels of cAMP by deregulating adenylate cyclase, which escalates the production of secretory fluid, and, in effect, causes watery and abundant diarrhea termed secretory diarrhea. This type of diarrhea with acute abdominal pain is characteristic for cholera $[9,20]$. Other enterotoxins yield a similar effect, but through a different path - lipopolysaccharide endotoxin through cGMP pathway [21], ciguatera toxin through calcium-dependent pathway and Shigella toxin through nitric oxide pathway. Each of them induces watery diarrhea. Another mechanism of non-inflammatory diarrhea, seen often in persistent diarrhea as well as rotavirus infections, uses the law of osmosis. In osmotic diarrhea poorly absorbable substance creates osmotic pressure across the mucosa of the intestine wall [9]. It is easy to fall into dehydration as liquids pass to the lumen of the intestine according to the concentration gradient. The diarrhea is frothy and exploding and ceases after fasting. Exudative, inflammatory diarrhea with blood, mucus and pus in stool (dysentery) is caused by bacteria that invade mucosa and release cytotoxins [4]. They act mostly in the distal part of the intestines - distal ileum and colon. Cytotoxins kill cells by suppressing the synthesis of proteins (shiga toxin produced by Shigella dysenteriae type 1), creating pores in the cell membrane (hemolysins released by Vibrio parahaemolyticus) or ceasing the extension of actin filaments. This type of diarrhea is usually accompanied by systemic symptoms - fever and a rise of inflammation markers in blood [9]. Some bacteria combine various diarrheal mechanisms and cause secretory and inflammatory diarrhea simultaneously - these are the capacities owned by C. jejuni, Salmonella spp. and Aeromonas spp. Among 
protozoa, E. histolytica causes a severe disease by creating ulcers on the intestine wall using cytolysis, proteases, toxins and phagocytosis. It can also spread to other organs, especially the liver, and reside within. Giardia attaches itself to the wall of the small intestine, but its virulence factors have not been yet discovered [9].

Diagnosis. Diarrhea without the inflammation component (fever or blood in stool) lasting less than 5 days usually does not require pathogen investigation $[9,10]$. Nonetheless, we should consider further diagnostics when the symptoms are severe, when there was an outbreak of symptoms in one group of travelers, when diarrhea is persistent, when the patient is immunodeficient or when in differential diagnosis we suspect that the patient may suffer from an inflammatory bowel disease. Choosing the right treatment should be guided by a thorough interview which, apart from the existing symptoms, focuses on the destination of the travel and the medical history of the patient. It is also crucial to know the incubation period of certain pathogens; generally, symptoms that persist no longer than 2 weeks indicate a bacterial or viral infection, while longer lasting cases suggest parasitic etiology and require specific treatment. Conventional methods of diagnostics include microbiological culture for bacteria, immunoenzymatic tests for viruses, and microscopic assessment of stool samples for parasites. If these methods appear to be insufficient, looking for pathogen's DNA in patient's blood will deepen the search [2]. However, diagnostics can encounter several challenges. For example, diarrhoeagenic $E$. coli shares part of its genetic sequence with commensal strains [15]. Also, the identification of $E$. histolytica is problematic because it is impossible to distinguish it microscopically from non-pathogenic E. dispar [9]. Apart from investigation to discover the pathogen which caused the disease, several common tests should also be performed, such as full blood count, liver enzymes, renal functioning, to assess the overall health of the patient [4].

Treatment. Most cases of travelers' diarrhea are mild and self-limiting and resolve without medical attention [7]. Many tourists receive pre-travel advice from their doctors and carry a TD kit with them to administer self-treatment if necessary. The main objective of self-treatment of a simple TD, which is not associated with any accompanying symptoms, is to compensate the loss of body fluid and to soothe the symptoms. Easy informal methods of rehydration include eating soup and drinking sugar-flavoured water and biting on salty crackers. Formal oral rehydration therapy is recommended to the most vulnerable groups of patients, e.g. infants, young children and the elderly, as well as to any patient with cholera-like diarrhea [3]. Diarrhea is not a contraindication against eating solid foods as they induce the recovery of damaged enterocytes [4]. In more severe cases antimicrobials (mentioned below) carried in travel- er's kit are to be self-administered by the patient. Despite self-treatment being a very common practice, there are several situations when medical attention is required. These include: lack of improvement after 24 hours of the initial onset of symptoms, high fever, severe abdominal pain, signs of dehydration, frequent vomiting, which makes it impossible to compensate the loss of fluids, blood stains in stool or melena, no rapid improvement after self-treatment and persistent diarrhea of more than 3-4 days. Severe or uncomfortable diarrhea is usually treated by a 3-day empirical course of wide-spectrum-antibiotics [3]. Antimicrobial treatment shortens the duration of symptoms to a day and a half (in comparison with the average of 4 days in cases of untreated TD) [8]. The common choice is fluoroquinolone (ciprofloxacin, $750 \mathrm{mg}$ once daily for 1 to 3 days) and azithromycin (500 mg once daily for 3 days or $1000 \mathrm{mg}$ in a single dose) as a second option [3, 8]. However, azithromycin should be considered as the first-line treatment option for tourists travelling to Southeast Asia for the reason that a majority of infections in the region are caused by Campylobacter, which shows $60 \%$ resistance to fluoroquinolones [1]. Rash, photosensitivity and GI complaints are rare side-effects of using fluoroquinolones. However, fluoroquinolones were found to interact with some drugs such as warfarin, phenytoin, ciclosporin and theophylline, as well as they are not recommended for pregnant women and small children. Although it acts more slowly than ciprofloxacin in Campylobacter-negative patients, azithromycin does not alter the pharmacokinetics of other drugs and is a good alternative for children (however, it has not been licensed for use by pregnant women). A relatively new antimicrobial is semisynthetic rifaximin. The studies have shown that in cases of a secretory diarrhea treatment with rifaximin (200 mg 3 times daily for 3 days) [8] is as effective as with ciprofloxacin [3]. It is not absorbed through the intestinal wall and thus it does not cause any systemic effects [4]. However, rifaximin has not been tested on patients presenting with diarrhea complicated by fever, systemic toxicity or blood stained stools, thus it is not recommended in such cases. Although antisecretory and antimotility agents, such as loperamide, will reduce the passage of stools even by $65 \%$, they may have a negative effect on the clinical course of diarrhea, especially in cases of an invasive infection; this is due to the fact that they cease the evacuation of the pathogen through the intestines and they have no direct effect on the disease-causing microorganisms [3]. Antibiotic treatment will note resolve diarrhea of viral etiology. However, most viral cases are mild and resolve spontaneously within 24-72 hours. On suspicion of a parasitic infection, persistent diarrhea should be treated with metronidazole, which is the treatment of choice in cases caused by Giardia intestinalis infection [4]. Each case of a diarrhea complicat- 
Table 3. Travelers' diarrhea management algorithm

\section{PRE-TRAVEL}

Pre-travel advice:

1. Definitions of TD and classification of severity.

2. Importance of oral rehydration through fluid and salt intake for all TD.

3. Information on effectiveness of treatments for TD and the risk of travel, TD and antibiotic use with the acquisition of multi-drug resistant bacteria.

4. Provision of empiric treatment medications as indicated by itinerary and practitioner-traveler determination.

5. Intra- and post-travel illness follow-up recommendations.

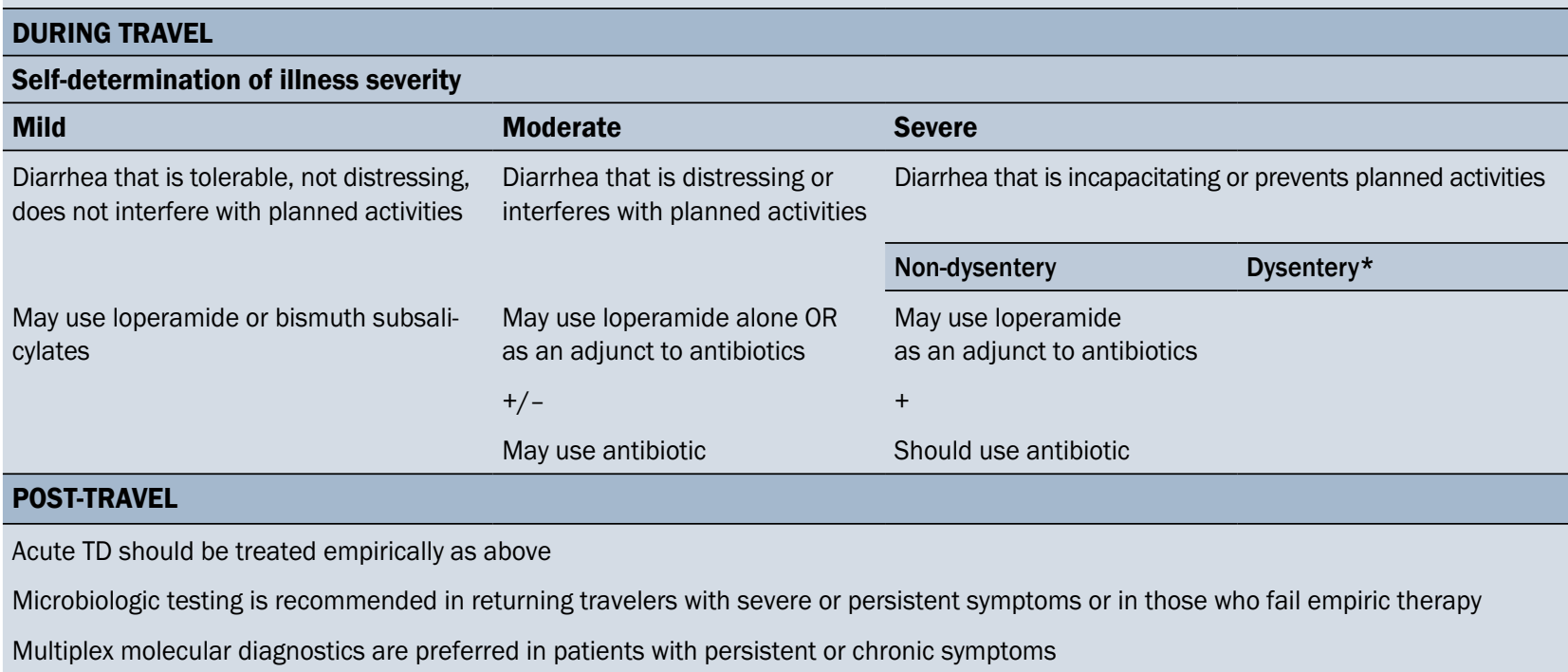

*All dysentery is considered severe. Source: Riddle M, et al. Guidelines for the prevention and treatment of travelers' diarrhea: a graded expert panel report. J Travel Med. 2017; 24(Suppl. 1): S57-S54 [22]; TD - travelers' diarrhea

ed by fever and bloody stools or cholera-like watery diarrhea should be further investigated by obtaining and assessing blood and stool samples; treatment should be adjusted according to test results (Table 3) [22].

\section{PERSISTENT OR REFRACTORY DIARRHEA}

Persistent diarrhea accounts for $2 \%$ of all TD cases. It is defined as diarrhea lasting more than 14 days, although in $1 \%$ of cases it may persist longer than 4 months. Refractory diarrhea is a diarrhea which does not respond to antibiotic therapy at all or relapses soon after the completion of treatment. In such cases multi-resistant bacteria or protozoa are usually found to be responsible for the infection. The etiology of persistent or refractory diarrhea often remains unknown, in spite of a wide range of available diagnostic methods. A number of different etiologies, not only infectious, should be taken into consideration. Initial investigation of persistent diarrhea should include, apart from a thorough interview, examination of at least 3 stool samples collected on different days, to be examined in the light microscopy for the presence of intestinal parasites, and for a bacterial culture (especially for Salmonella, Shigella and Campylobacter) [8]. Stool should also be examined for fecal leukocytes, lactoferrin and occult blood. For as long as the results of the above-mentioned tests are awaited, the patient should avoid dairy products and should take the hydrogen breath test for lactose intolerance if dietary restriction was inconclusive. Further investigations include Gl endoscopy with a biopsy of the small or the large intestine, if the symptoms indicate a distal infection. If major symptoms still exist and weight loss is progressive, the patient should be examined for celiac disease by measuring the serum anti-transglutaminase antibodies [10]. Some patients develop symptoms of inflammatory bowel disease after a trip to the tropics. Other possible diagnoses include neoplasia and endocrinopathy. Additionally, some medications could be the cause of persistent diarrhea.

In the absence of a specific etiologic diagnosis, the following therapy is suggested:

- discontinuation of medications which can cause diarrhea (e.g. laxatives, antibiotics, diuretics);

- administration of antimotility agents, such as loperamide; bismuth subsalicylate; probiotics, e.g. Lactobacillus or Saccharomyces, which prevent antibiotic-associated diarrhea;

- dietary modification to avoid food which irritates the bowel, i.e. alcohol, spicy food, caffeine;

- cholestyramine resin to bind bile-acids;

- bulk agents, e.g. psyllium, which increase fecal capacity of holding water [10]. 


\section{POST-INFECTIOUS IRRITABLE BOWEL SYNDROME (PI-IBS)}

Post-infectious irritable bowel syndrome is a problem affecting $3 \%$ to $17 \%$ of patients after they had experienced $\operatorname{TD}[8,23]$. When chronic enteric infection and organic GI disease are excluded, symptoms such as abdominal pain and altered bowel movement habits are suggestive of an irritable bowel syndrome which has developed after gastroenteritis or TD [23, 24]. There are some generally recognised factors which are associated with the development of PI-IBS, e.g. the severity of TD, the number of TD episodes, the history of pre-travel diarrhea or other adverse life events, and the etiology factor of TD being a heat-labile toxin-producing ETEC. Other risk factors include young age and female gender, as well as personality features, e.g. being prone to stress, anxiety, having a high level of neuroticism and somatisation. If TD is caused by a bacteria which destroys the intestine wall (e.g. Salmonella, Shigella or Campylobacter), the risk of developing PI-IBS afterwards further increases [24]. Giardiasis often imitates the PI-IBS, causing malabsorption and subsequent bloating, nausea and vomiting [18]. The results of a prospective cohort study suggest that TD patients treated with antibiotics were less likely to develop PI-IBS than patients who cured spontaneously [25], although some meta-analyses include antibiotics as a risk factor [24]. More studies need to be performed to assess the etiologic factors of PI-IBS and in result to define the right treatment strategies [18].

\section{PREVENTION OF GASTROINTESTINAL INFECTIONS}

Prevention against $\mathrm{Gl}$ infections should begin well before the travel by seeking advice from a family doctor or a specialist in travel medicine. This advice should include such topics as hand hygiene, choice of safe food and beverages and fluid replacement. It should mention the situations when seeking professional medical help is crucial. Unfortunately only $2 \%$ patients comply with the instructions [11].

The common advice to avoid street food is hard to follow as trying local cuisine is considered as a part of cultural experience [13]. Local street food is often described as the most delicious by the ones who dared to try it. Therefore, the patient should at least remember that freshly prepared food which is served steaming hot (at least 70 centigrade degrees), peeled or highly citrus fruits and dry foods are the safest [11]. Old rule "Cook it, boil it, peel it or forget it" still functions well [4].

Many bacteria can be swallowed with a sip of water, especially Shigella which has a low infective dose. A traveller should avoid tap water and ice cubes [3, 4], and stick to purified bottled water. It is to be remembered that tap water is often sold as purified water in bottles in many developing countries [3]. Carbonated water is safer to drink as it has a lower $\mathrm{pH}$ which kills enteropathogenic bacteria; there were some cases of diarrhea in Mexico and Portugal caused by contaminated noncarbonated bottled water. Boiling water for 1 min kills most of the bacteria (on high altitudes above $2000 \mathrm{~m}$ water should be boiled for at least $3 \mathrm{~min}$ ) [26]. Alcohol consumption has not been identified as a preventive method nor a risk factor of TD [6].

Another form of pre-travel prevention is vaccination. There are several vaccines recommended for travelers: against typhoid fever, viral hepatitis $A$, and cholera. The latter is known in several countries like Canada and Sweden as "a travelers' diarrhea vaccine", as it gives a partial (7\%) cross-protection against heat-labile toxin-producing ETEC. Although its protective efficacy against ETEC lasts 3 months only, some patients could benefit from getting vaccinated [4].

Although there is an improvement of hygiene status in developing countries [11], washing hands with water and soap or cleaning them with an antibacterial gel should never be avoided [4]. Bismuth subsalicylate taken as a preventive medication 4 times a day during travel reduces the risk of TD by $65 \%$. Its adverse effects include turning the tongue and stools black - the latter should be considered when diagnosing bloody stools. Salicylate compounds should be avoided by patients who take anticoagulants or salicylate on the long term [8]. The use of synbiotics, prebiotics and probiotics has not been supported by any study thus its use in order to prevent TD is not recommended [13]. Chemoprophylaxis is usually not recommended because of higher cost than eventual self-treatment, although there are four groups of people for which we should propose this form of prevention. These include people who take short 3-5-day trips and cannot be trapped in a hotel room with Gl symptoms (i.e. sportsmen, businessmen, musicians, lecturers), patients who have already experienced TD and can be considered as prone to it, immunodeficient patients suffering from chronic diseases, AIDS, cancer, heart failure or diabetes treated with insulin, and the last group - patients who have requested for chemoprophylaxis [27]. A popular drug is rifaximin, which would prevent $72 \%$ of infections [4].

\section{CONCLUSIONS}

Gastrointestinal disorders remain the most common problem among travelers that can ruin every vacation or an international business meeting. In most cases the symptoms are either self-limiting or disappear after easy empirical 3-day antimicrobial treatment. Doctors in home countries will encounter either patients with acute diarrhea which started at the end of the trip, or persistent diarrhea, mostly caused by parasites. Sometimes travel masks the real reason of sickness, so non-infectious and post-infec- 
tious diagnoses should also be taken into consideration. These include lactose intolerance, celiac disease, neoplasm, post-infectious irritable bowel syndrome, and side-effects of the medications.

\section{REFERENCES}

1. Wyss MN, Steffen R, Dhupdale NY, et al. Management of travelers' diarrhea by local physicians in tropical and subtropical countries-a questionnaire survey. J Travel Med. 2009; 16(3): 186-190, doi: 10.1111/j.1708-8305.2009.00335.x, indexed in Pubmed: 19538579.

2. Jiang ZD, Lowe B, Verenkar MP, et al. Prevalence of enteric pathogens among international travelers with diarrhea acquired in Kenya (Mombasa), India (Goa), or Jamaica (Montego Bay). J Infect Dis. 2002; 185(4): 497-502, doi: 10.1086/338834, indexed in Pubmed: 11865402.

3. Al-Abri SS, Beeching NJ, Nye FJ. Traveller's diarrhoea. Lancet Infect Dis. 2005; 5(6): 349-360, doi: 10.1016/S1473-3099(05)70139-0, indexed in Pubmed: 15919621.

4. Korzeniewski K. Gastrointestinal disorders in returning travellers. FMR 2018; 12(4): 115-126 [in Polish.

5. Vilkman K, Pakkanen SH, Lääveri T, et al. Travelers' health problems and behavior: prospective study with post-travel follow-up. BMC Infect Dis. 2016; 16: 328, doi: 10.1186/s12879-016-1682-0, indexed in Pubmed: 27412525.

6. Pitzurra R, Steffen R, Tschopp A, et al. Diarrhoea in a large prospective cohort of European travellers to resource-limited destinations. BMC Infect Dis. 2010; 10: 231, doi: 10.1186/1471-2334-10-231, indexed in Pubmed: 20684768.

7. Greenwood Z, Black J, Weld L, et al. GeoSentinel Surveillance Network. Gastrointestinal infection among international travelers globally. J Travel Med. 2008; 15(4): 221-228, doi: 10.1111/j. 1708-8305.2008.00203.x, indexed in Pubmed: 18666921.

8. Steffen R, Hill DR, DuPont HL. Traveler's diarrhea: a clinical review. JAMA. 2015; 313(1): 71-80, doi: 10.1001/jama.2014.17006, indexed in Pubmed: 25562268.

9. Gascón J. Epidemiology, etiology and pathophysiology of traveler's diarrhea. Digestion. 2006; 73 Suppl 1: 102-108, doi: 10.1159/000089785, indexed in Pubmed: 16498258.

10. Canada Communicable Disease Report: Statement on persistent diarrhea in the returned traveller. Public Health Agency of Canada. 15 February 2006, Vol. 32, ACS-1.

11. Steffen R. Epidemiology of travellers' diarrhea. J Travel Med. 2017; 24(suppl1): S2-S5, doi: 10.1093/jtm/taw072, indexed in Pubmed: 28520996.

12. von Sonnenburg F, Tornieporth N, Waiyaki P, et al. Risk and aetiology of diarrhoea at various tourist destinations. Lancet. 2000; 356(9224): 133-134, doi: 10.1016/S0140-6736(00)02451-X, indexed in Pubmed: 10963251.

13. DuPont H, Khan F. Travelers' diarrhea: epidemiology, microbiology, prevention, and therapy. J Travel Med. 1994; 1(2): 84-93, doi: 10.1111/j.1708-8305.1994.tb00568.x.
14. Lääveri T, Vilkman K, Pakkanen SH, et al. A prospective study of travellers' diarrhoea: analysis of pathogen findings by destination in various (sub)tropical regions. Clin Microbiol Infect. 2018; 24(8): 908.e9-908. e16, doi: 10.1016/j.cmi.2017.10.034, indexed in Pubmed: 29133155.

15. Jiang ZD, DuPont HL. Etiology of travellers' diarrhea. J Travel Med. 2017; 24(suppl_1): S13-S16, doi: 10.1093/jtm/tax003, indexed in Pubmed: 28521001.

16. Vila J, Ruiz J, Gallardo F, et al. Aeromonas spp. and traveler's diarrhea: clinical features and antimicrobial resistance. Emerg Infect Dis. 2003; 9(5): 552-555, doi: 10.3201/eid0905.020451, indexed in Pubmed: 12737738.

17. Launders NJ, Nichols GL, Cartwright R, et al. Self-reported stomach upset in travellers on cruise-based and land-based package holidays. PLoS One. 2014; 9(1): e83425, doi: 10.1371/journal. pone.0083425, indexed in Pubmed: 24427271.

18. Duplessis CA, Gutierrez RL, Porter CK. Review: chronic and persistent diarrhea with a focus in the returning traveler. Trop Dis Travel Med Vaccines. 2017; 3: 9, doi: 10.1186/s40794-017-0052-2, indexed in Pubmed: 28883979.

19. Castelli F, Pezzoli C, Tomasoni L. Epidemiology of travelers' diarrhea. J Travel Med. 2001; 8(Suppl 2): S26-S30, doi: 10.1111/j.17088305.2001.tb00543.x, indexed in Pubmed: 12186670.

20. Bavastrelli M, Bertucci $P$, Midulla M, et al. Ciguatera fish poisoning: an emerging syndrome in Italian travelers. J Travel Med. 2001; 8(3): 139142, doi: 10.2310/7060.2001.24387, indexed in Pubmed: 11468116.

21. Fasano A. Toxins and the gut: role in human disease. Gut. 2002; 50 Suppl 3: III9-II14, doi: 10.1136/gut.50.suppl_3.iii9, indexed in Pubmed: 11953326.

22. Riddle MS, Connor BA, Beeching NJ, et al. Guidelines for the prevention and treatment of travelers' diarrhea: a graded expert panel report. J Travel Med. 2017; 24(suppl_1): S57-S74, doi: 10.1093/ jtm/tax026, indexed in Pubmed: 28521004.

23. Mutsch M, Pitzurra R, Hatz C, et al. Post-infectious sequelae of travelers' diarrhea: irritable bowel syndrome. J Travel Med. 2014; 21(2): 141-143, doi: 10.1111/jtm.12094_1, indexed in Pubmed: 24593027.

24. Schwille-Kiuntke J, Mazurak N, Enck P. Systematic review with meta-analysis: post-infectious irritable bowel syndrome after travellers' diarrhoea. Aliment Pharmacol Ther. 2015; 41(11): 1029-1037, doi: 10.1111/apt.13199, indexed in Pubmed: 25871571.

25. Lalani T, Maguire JD, Grant EM, et al. Epidemiology and self-treatment of travelers' diarrhea in a large, prospective cohort of department of defense beneficiaries. J Travel Med. 2015; 22(3): 152-160, doi: 10.1111/jtm.12179, indexed in Pubmed: 25483360.

26. Diemert DJ. Prevention and self-treatment of traveler's diarrhea. Clin Microbiol Rev. 2006; 19(3): 583-594, doi: 10.1128/CMR.00052-05, indexed in Pubmed: 16847088.

27. DuPont HL. Therapy for and prevention of traveler's diarrhea. Clin Infect Dis. 2007; 45 Suppl 1: S78-S84, doi: 10.1086/518155, indexed in Pubmed: 17582576. 